\title{
O livro e a formaçáo do leitor-escritor: trilhas da extensão na educação básica
}

\author{
Andrea da Paixão Fernandes* \\ Jacqueline de Fátima dos Santos de Morais** \\ Lincoln Tavares Silva** \\ Patrícia Braun ${ }^{* * * *}$
}

\begin{abstract}
Resumo
O Instituto de Aplicação Fernando Rodrigues da Silveira, da Universidade do Estado do Rio de Janeiro (CAp-UERJ), tem como importante objetivo o investimento na formaçáo de um cidadáo crítico e criativo. Buscamos, para isso, práticas pedagógicas que desenvolvam a leitura e a escrita com sentido e uso social real. Tais açóes constituem uma das marcas da concepção pedagógica da instituição. O projeto de extensão universitária "O livro e a formação do leitor-escritor" visa a tornar público, por meio da publicação de textos escritos de vários gêneros literários e imagéticos, a rica produção dos nossos estudantes. Como consequência desse investimento, desde o ano de 2004 o CAp-UERJ participa do Projeto Redação, promovido pelo jornal Folha Dirigida e pela Fundaçáo Biblioteca Nacional. Esse projeto consiste na construção de uma obra literária a cada ano, tendo como autores estudantes de educação básica. Em nosso caso, essa parceria possibilita e potencializa a divulgaçáo das produçôes textuais dos estudantes do $1^{\circ}$ ano do Ensino Fundamental ao $3^{\circ}$ ano do Ensino Médio. Nosso artigo traz a experiência vivida nesses anos de desenvolvimento de projeto. Palavras-chave: produção de texto, prática pedagógica, escola básica.
\end{abstract}

Books and the formation of the reader-writer: outreach paths in basic education

\begin{abstract}
Abstrac
One of the major objectives of the Instituto de Aplicaçáo Fernando Rodrigues da Silveira, at the Universidade do Estado do Rio de Janeiro (Cap-UERJ), is to invest in the formation of critical, creative citizens. To achieve this aim, teaching practices which encourage reading and writing with meaning and real social use, are adopted. These actions are a hallmark of the Instituto's
\end{abstract}

* Professora do Instituto de Aplicação Fernando Rodrigues da Silveira (CAp-UERJ) e da Prefeitura da Cidade do Rio de Janeiro. Doutoranda do Programa de Pós-Graduação em Educação da Unicamp. E-mail: fernandes.ap@globo.com

* Professora do Instituto de Aplicação Fernando Rodrigues da Silveira (CAp-UERJ) e da Faculdade de Formação de Professores da UERJ. Doutora em Educaçáo pela Unicamp. E-mail: jacquelinemorais@hotmail.com

*** Professor do Instituto de Aplicação Fernando Rodrigues da Silveira (CAp-UERJ). Doutorando do Programa de Pós-Graduação em Educação da FEUSP. E-mail: lincolntsilva@hotmail.com

**** Professora do Instituto de Aplicação Fernando Rodrigues da Silveira (CAp-UERJ). Doutoranda do Programa de Pós-Graduaçáo em Educação da UERJ. E-mail: p.braun@terra.com.br 
concept of pedagogy. The aim of the University outreach project "Books and the formation of the reader-writer" is to publicize the students' wealth of production by publishing their texts written in the most varied literary and imaginative genres. As a result of this investment, from 2004 onwards, the Cap-UERJ has been participating in the Writing Project, sponsored by both the Folha Dirigida newspaper and the National Library Foundation. This project involves the annual production of a literary work written by students of basic education. In our case, with this partnership the writings of students from $1^{\text {st }}$ year Elementary School to $3^{\text {rd }}$ year High School can be published. This article presents the experience of the project over these years.

Keywords: Writing texts, Pedagogical practice, Elementary School.

Dupla delícia: o livro traz a vantagem de a gente poder estar só e ao mesmo tempo acompanhado.

(Mario Quintana)

\section{Conhecendo o CAp-UERJ}

Instituto de Aplicação Fernando Rodrigues da Silveira, ou CAp-UERJ, como é mais conhecido por sua antiga denominação - Colégio de Aplicação da UERJ -, é uma unidade acadêmica da Universidade do Estado do Rio de Janeiro, tendo iniciado suas aulas em $1^{\circ}$ de abril de 1957 . Nossa escola, ao assumir-se e atuar como instituto, pode estabelecer diálogos, nos diferentes campos de saberes, entre a formação docente (inicial e continuada) e o desenvolvimento de açôes e práticas de ensino, pesquisa, extensão e gestão, sempre voltadas para a articulação entre educação básica e superior. Para tanto, nessas açóes se conduz como uma típica unidade universitária, ao desenvolver planejamentos e projetos que buscam contemplar os pilares básicos de sustentação e de caracterização do universo acadêmico universitário. A escola básica, na nossa concepção, não pode ser um apêndice, e sim o centro das práticas e reflexôes que norteiam o campo de atuação dos licenciandos e dos estudantes de educação básica, sob a orientação e o acompanhamento do corpo docente, com o apoio de outros profissionais que exercem papéis educativos variados (pedagogos, psicólogos, assistentes sociais, agentes educadores, técnico-administrativos, entre outros). Desta forma, ao assumirmos nossa condição de Instituto e, ao mesmo tempo, como locus privilegiado de ensino, que vai do $1^{\circ}$ ano do Ensino Fundamental ao 
fim do Ensino Médio, buscamos nos afastar de um certo colonialismo, ao e nos colocarmos contra o desperdício de nossa experiência (SANTOS, 2006).

Reconhecido por muitos como instituição de excelência, o CAp-UERJ é destacado pelo desempenho de seus estudantes em vestibulares e exames nacionais (Provinha Brasil, Prova Brasil e Enem) dos quais tem participado como pertencente ao sistema público de ensino. Agregam-se a esses dados as expectativas das famílias que buscam, ano após ano, o ingresso de seus filhos e filhas em uma escola pública que é vivida, especialmente para as camadas populares, como uma ilusão fecunda (SPOSITO, 1993), pois é percebida como de qualidade. Se a esse foco podemos atribuir alguma positivação, por outro lado explicita-se a impossibilidade de atendimento a todos que buscam, seja no sorteio público, seja na prova de acesso às vagas nos diferentes momentos do Ensino Fundamental em nossa instituição, ensino de qualidade.

Por não centrarmos nossas açốes na lógica da excelência exclusiva ou do ranqueamento cristalizado, neste texto buscamos compartilhar algumas experiências docentes, não para que sejam disseminadas em outros espaços-tempo escolares de nosso país, mas para que, mesmo revelando contradiçóes e limites, mostrem uma escola que se afirma em movimento. Isto porque defendemos o respeito às realidades locais, bem como às decisões da comunidade escolar sobre as propostas pedagógicas, estas planejadas de forma coletiva e contextualizada nas unidades escolares dos diferentes sistemas públicos de educação, mesmo quando parcerias externas estiverem envolvidas nessas açóes.

Sendo uma unidade acadêmica vinculada a uma universidade pública, as atividades de ensino de nossa escola desdobram-se em dois níveis articulados: a educação básica e o ensino superior, mediados e integrados pelas atividades de pesquisa, extensão e ensino. Neste artigo focaremos, por sua importância e repercussão, um dos inúmeros projetos extensionistas que temos realizado: "O livro e a formação do leitor-escritor". Este tem mobilizado intensamente todo o colégio e criado múltiplas possibilidades de trabalho pedagógico, além de variados desdobramentos com a comunidade interna e externa ao CAp-UERJ, tanto no que se refere ao ensino quanto à pesquisa.

\section{O projeto de extensão "O livro e a formaçáo do leitor-escritor"}

O CAp-UERJ vem, ao longo de sua história, investindo na formação de um estudante que seja ao mesmo tempo leitor e escritor competente: capaz de interagir no mundo de forma crítica e criativa, a partir da apropria- 
ção e da produção de diferentes modalidades de linguagem, em múltiplas situaçóes, tanto escolares quanto de vida.

Desta forma, nosso trabalho pedagógico, no que tange à leitura e à escrita, estimula a formação do leitor-escritor em açóes pedagógicas que tenham visibilidade e impliquem interaçôes sociais mais amplas que apenas na escola.

É a partir desse pressuposto teórico-epistemológico que ganha corpo em 2004 a proposta de produção de livros coletivos no CAp-UERJ, com autoria dos estudantes de nossa escola, orientados por seus professores.

A partir de uma parceria entre três instituiçóes, o Instituto de Aplicação da UERJ, o jornal Folha Dirigida e a Fundação Biblioteca Nacional, "O livro e a formação do leitor-escritor" se inscreve e se afirma como projeto extensionista.

Para nós, docentes do CAp-UERJ, a parceria estabelecida com o jornal Folha Dirigida e a Fundação Biblioteca Nacional potencializa uma ação que faz parte da trajetória e da construção da nossa história institucional: o trabalho de extensão.

Desta maneira, entendemos extensão como uma das funções da universidade, a nutrir tanto a pesquisa quanto o ensino, pressupondo uma tríade em diálogo e retroalimentação permanente. Não defendemos uma concepção que a reduza à prestação de serviços, numa perspectiva que podemos classificar de assistencialista. Embora respeitemos como uma possibilidade de ação, nossa perspectiva vai no sentido de assumir a extensão como princípio educativo, tal como entendido por Gramsci (1989, p. 130). Assim, tencionamos que o projeto "O livro e a formação do leitor-escritor" contribua para o processo educativo de alunos, professores, pais e de toda a comunidade. Trabalhamos no sentido de que esse projeto possa, além de provocar a descoberta de novos sentidos, tanto para a produção escrita dos nossos estudantes quanto para os fazeres docentes relativos à língua escrita, provocar na comunidade escolar e exterior a ela uma outra relação com a leitura e a escrita, na medida em que a produção textual de nossos alunos, nesse projeto, tem alcance inimaginável.

Como processo educativo, a implementação desse projeto na escola se configurou como mais uma possibilidade de dar voz aos nossos estudantes, que, sob orientação de seus professores, podem escrever e tornar públicas suas narrativas, experiências, argumentaçôes, visôes de mundo, em diferentes estilos literários. 
Nesse movimento, desde o ano de 2004 obras literárias de autoria de nossos estudantes, abrangendo a totalidade dos anos de escolaridade, ou seja, do $1^{\circ}$ ano do Ensino Fundamental ao $3^{\circ}$ ano do Ensino Médio, vêm sendo produzidas e publicadas.

A equipe de trabalho é composta, ao longo dos anos de existência do projeto, por professores de diferentes anos de escolaridade e de disciplinas do Ensino Fundamental e Médio, que inserem a produção textual nos seus planejamentos e projetos de trabalho. Cabe ressaltar que, dessa forma, a elaboração do texto para o livro se constrói a partir da realidade de trabalho nas/pelas disciplinas, respeitando-se os gêneros textuais e as temáticas trabalhadas em cada ano de escolaridade. $O$ projeto tem contado com a participação direta de mais de 180 alunos e 30 professores a cada ano.

\section{A importância da escrita com sentido, com uso social, na escola e para além dela}

A escola, em sua trajetória como agente de formação de indivíduos, tem, no conjunto de suas atribuiçóes, a formação de estudantes que sejam leitores e escritores críticos. Ou, pelo menos, é nesse sentido que acreditamos que o espaço escolar deva se constituir quando se fala de aprender a ler e escrever. No entanto, sabemos também que nem sempre esse viés é privilegiado. Assim, muitas vezes, a língua é ensinada sem que os sujeitos aprendentes estejam mergulhados na sua corrente viva.

Neste sentido é importante levarmos em consideração, na escola, o que afirma Bakhtin (1981, p. 72):

A palavra revela-se, no momento de sua expressão, como o produto da interação viva das relaçóes sociais. [...] Os sujeitos não recebem a língua pronta para ser usada. [...] eles penetram na corrente da comunicaçáo verbal, ou melhor, somente quando mergulham nessa corrente é que a sua consciência desperta e começa a operar.

A partir desse princípio temos, no CAp-UERJ, investido em atividades que possibilitem a produção da palavra como produto da interação viva das relaçôes sociais.

Assim, as propostas nesse campo de conhecimento precisam ser permeadas por uma prática contextualizada, dinâmica, atual e principalmente que 
envolva o ambiente social dos estudantes. Defendemos que qualquer proposta de ensino que envolva a produção textual na escola deve levar em conta, entre outras, as questóes: quem escreve? Para quem? Para quê? Por quê? (GERALDI, 1996). No entanto, não estamos afirmando que toda proposta de ensino da língua (e da produção textual, em especial) deva partir somente do contexto social dos estudantes. Se assim o fosse, estaríamos restringindo possibilidades de novas experiências. Afirmamos, porém, a importância de ampliarmos, na escola, as possibilidades de os estudantes verem e entenderem o mundo, muitos mundos, outros e novos mundos, que não apenas aqueles pelos quais circulam.

Como afirma Garcia (1998), a apropriação da leitura por todos é um direito político, especialmente das classes populares, e um dever da escola que se compromete com a emancipação de seus estudantes. Assim, propor um projeto de produção de texto na escola, que caminhe por entre a língua viva, estimulando a formação da autoria e da autonomia intelectual, vista não como um processo individual, mas como essencialmente dialógico e solidário, é, antes de tudo, uma opção política e epistemológica. Desta forma, entendemos que o projeto "O livro e a formaçâo do leitor-escritor" contribui para a funçáo da escola na formaçáo do sujeito leitor-escritor que questiona, que é conectado com o mundo e que sempre está disposto a conhecer, aprender, lendo e escrevendo.

\section{A construçáo da escrita pelos estudantes do CAp-UERJ e os diálogos temáticos}

Diversos são os temas que vêm norteando o trabalho de produção textual até o momento (Fig. 1). No seu primeiro ano, o meio ambiente foi o tema norteador. A produção textual náo se caracterizou por se tratar de um ambiente "pelo meio", abstrato ou afastado das preocupaçóes que têm afligido a humanidade com um olhar sobre o presente, que não se esqueceu das críticas aos desvios do passado, sem perder de vista as possibilidades para as geraçóes futuras.

Em 2005, optamos por deixar o tema livre, mas uma análise dos dois primeiros livros permite constatar que o viés socioambiental foi uma tônica. A ele se somaram outros temas do cotidiano de nossa cidade, da política, da adolescência e também da realidade regional de nosso país, precipitando concepçóes de diversidade cultural. No ano de 2006, o tema valores orientou 
os escritos de nossos meninos e meninas nas diferentes faixas etárias. Mais uma vez, cabe registrar que a sustentabilidade da temática socioambiental se fez presente em muitos dos textos, sobretudo nos das turmas dos anos iniciais do Ensino Fundamental. Esse livro também foi marcado pelo posicionamento dos alunos em relação à greve dos trabalhadores (docentes e técnico-administrativos) da UERJ. Tal conjuntura se inseriu no contexto dos direitos sociais, cívicos e trabalhistas, ampliando a noção de valores de respeito e amizade, sem desprezar a crítica às instituiçóes brasileiras que produzem e reproduzem desigualdades (televisão, partidos, corrupção de advogados, entre outros).

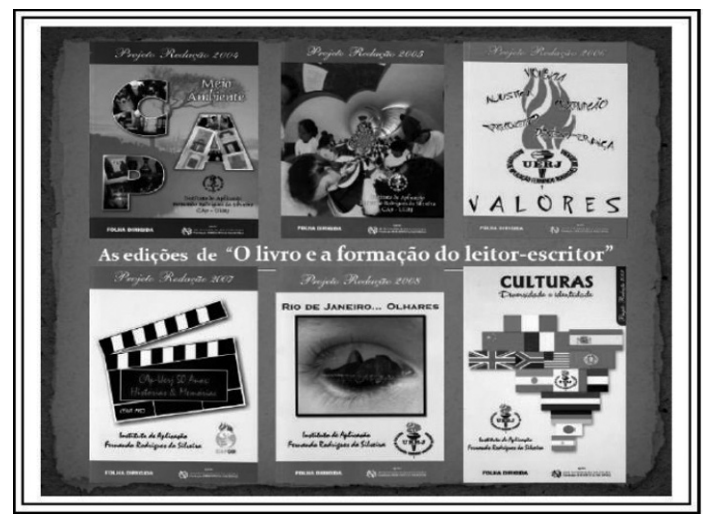

Fig. 1 - Capas dos livros produzidos de 2004 a 2009

Em meio a textos coletivos e individuais, diferentes estilos textuais, tais como contos, cartas, cordéis, poesias, se fizeram presentes.

O ano de 2007, entretanto, foi um marco na história do colégio. Completamos 50 anos. Decidimos, então, contar a nossa história. Mas ousamos fazê-lo através das várias lentes, de centenas de olhares. O livro $C A p$ -UERJ 50 anos: histórias e memórias, ao contar as histórias do CAp-UERJ, reconstrói suas memórias e traz, para quem chega, os diferentes olhares dos estudantes. O próximo e o distante se aproximaram sob ópticas distintas, mas náo deixaram de se fazer presentes o apelo político, a crítica ao governo, a discussão das condiçōes físicas do Instituto, assim como reflexôes sobre os bons resultados alcançados pela escola, bem como a sua qualidade educacional.

Em 2008, imbuídos do desejo de falar de nossa gente, de nossa cidade, de Machado de Assis, que tấo bem narrou o Rio, das histórias do Rio 
Antigo, contadas e encantadas por cariocas (de nascimento e de coração), produzimos Rio de Janeiro... olhares. Mais uma vez, encontramos os olhares dos nossos escritores. Eram histórias que traziam a abrangência e a complexidade do tema, com a ousadia de falar da nossa gente, do nosso jeito de ser, da nossa cultura e de como é ser carioca na cidade do Rio de Janeiro.

No ano de 2009, a temática trazia a preocupaçáo de pautarmos o diálogo e, nesse processo, a pesquisa sobre um tema bastante discutido na atualidade: a cultura, sua diversidade e multiplicidade. Era chegada a hora de propormos aos nossos estudantes que pesquisassem, refletissem e problematizassem a riqueza sociocultural e a diversidade que caracteriza o Brasil e o povo brasileiro.

Cabe ressaltar que o trabalho de produção dos textos não se faz tecido individual ou isoladamente. A tessitura dos textos pressupóe pesquisa investigativa da temática de cada livro, uma reflexão sobre cada produçáo, constituindo-se como etapas (ou caminhos possíveis) para cada texto. Todas as etapas fazem parte da construçáo da obra. Embora não caiba neste texto aprofundarmos a análise sobre os diversos textos produzidos pelos estudantes, apresentaremos, além do mosaico das imagens de alguns deles (Fig. 2), em diferentes anos da produçáo, uma experiência concreta de produção textual de uma das turmas dos anos iniciais de escolaridade ( $3^{\circ}$ ano do Ensino Fundamental).

Além dos aspectos já apresentados, é importante ressaltar que esse trabalho nos dá pistas de como o prazer de ler e de escrever pode ser ampliado quando estão em jogo experiências significativas.

Nosso intento visa, desde sua origem, a possibilitar uma aprendizagem conjunta para os diferentes sujeitos envolvidos no projeto, além de potencializar o desenvolvimento de práticas leitoras, investigativas e autoras, como possibilidade de desenvolvimento do processo de ensino-aprendizagem das crianças e dos jovens estudantes do CAp-UERJ, por meio de produçóes textuais individuais ou coletivas. Esses objetivos vêm sendo construídos e consolidados a cada ano de realização desse trabalho.

Como decorrência das marcas da ampliação dessa caminhada, a partir do ano de 2008 o trabalho adquire um caráter transdisciplinar, deixando de ter sua orientação focada nos professores dos anos iniciais do Ensino Fundamental e nos de Língua Portuguesa, e, por sua vez, propondo uma relação dialógica e participativa com as diferentes áreas do conhecimento. Além disso, passamos a incorporar de modo mais efetivo a produção visual dos estudantes, por meio de imagens resultantes de processos coletivos e 
contextualizados de aprendizado, significando novas formas e possibilidades de leitura dos textos, dos temas e do mundo.

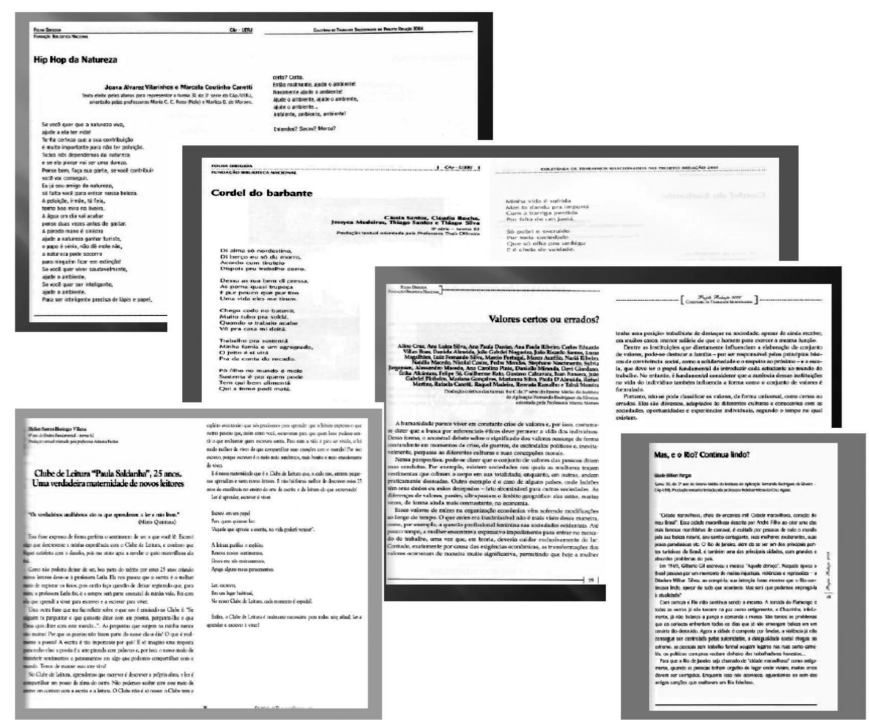

Fig. 2 - Mosaico com alguns dos textos produzidos pelos estudantes, sob a orientação de professores de diferentes anos de escolaridade

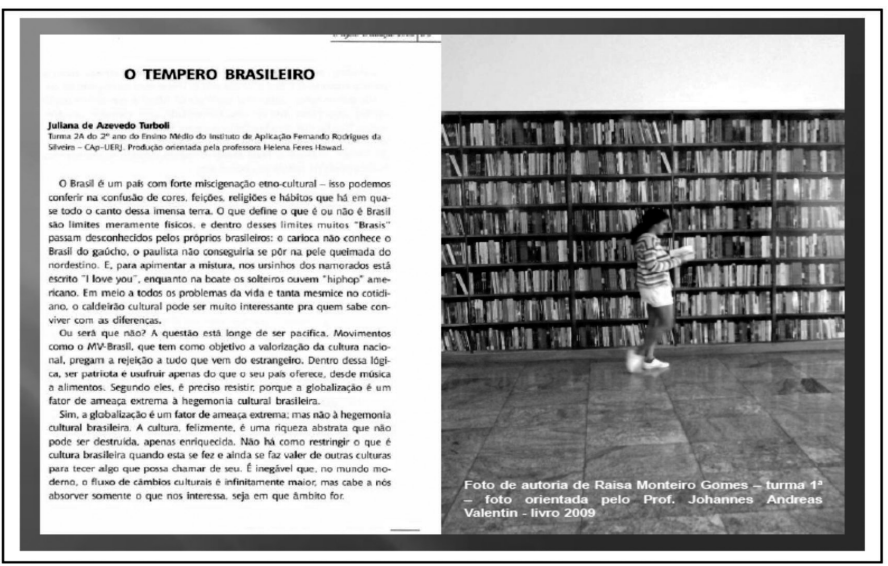

Fig. 3 - Diferentes leituras, múltiplas possibilidades, textos e contextos 
Essa inovação representa não só a ampliação propriamente dita, como também o enriquecimento dessa história em construção, por meio das possibilidades e perspectivas de diálogos entre as áreas e por entre elas.

Ao trazer para este texto as trilhas de nosso projeto de extensão, conforme apontado no título deste artigo, queremos afirmar a importância de reconstruirmos as memórias desse percurso.

Neste sentido, trazer para este artigo alguns dos textos publicados ao longo dos seis anos de existência do projeto de extensão, que aqui retratamos, representa uma oportunidade não apenas de socializar a produção de nossos estudantes para outros leitores, como também de preservar uma história vivida coletivamente.

Para melhor exemplificarmos nossas trajetórias - que são múltiplas -, optamos por reproduzir neste artigo alguns dos textos tecidos para os livros. Não nos preocupamos em atrelar a quantidade de textos aos anos de existência do projeto ou aos livros publicados, mas apenas em possibilitar, por meio dos textos que aqui poderão ser (re)lidos, que outras vozes se somem às nossas, de autores deste artigo. Vozes essas de outros autores, os dos livros.

Analisando os textos produzidos nas edições dos últimos cinco anos, consideramos que a perspectiva sócio-histórica e os processos constituídos a partir das lembranças ressignificadas encontram lugar privilegiado nessas produçóes, sobretudo dos últimos dois anos. A perspectiva socioambiental também se encontra presente em muitos dos textos das diversas ediçôes. Os livros que trazem como temática o cinquentenário do Instituto de Aplicação Fernando Rodrigues da Silveira e o mais recente, que nos permite um mergulho pelas histórias que contam e encantam a cidade do Rio de Janeiro, nos permitem viajar pelos recantos de muitas memórias.

O exercício de recuperação da memória nos permite desenvolver com os estudantes a habilidade da pesquisa em diferentes fontes (documentos, testemunhos, músicas etc). Permite-nos, ainda, recorrer à literatura existente e estabelecer um reencontro com as práticas leitoras. Reencontro este que se faz permanentemente no Instituto de Aplicação.

\section{Repercussóes do projeto na escola e na vida dos estudantes}

Pensar sobre as repercussóes do projeto "O livro e a formação do leitor-escritor" é, antes de mais nada, tratar de sua própria razão de ser. À medida que as açóes tornam-se parte do cotidiano da escola, elas tendem a 
produzir seu espaço próprio, sua "territorialização" e, portanto, criam uma cultura no âmbito escolar.

Desde a primeira produção, houve uma preocupação com o princípio participativo e coletivo da elaboração dos textos do livro. Para tanto, a temática transversalizada contribuiu muito para a elaboração dos diferentes textos. Tal concepção retroalimentou-se nas açóes e práticas docentes cotidianas e serviu de caminho sustentável para aproximar gradativamente os estudantes entre si e com seus textos. Esse fato pode ser evidenciado no depoimento de uma docente dos anos iniciais do Ensino Fundamental para o jornal Folha Dirigida, uma das parceiras que vem publicando reportagens sobre o projeto. Diz a professora Andréa Fernandes':

Eles ainda estão naquela fase de elaboração da escrita. Quando a gente trabalha coletivamente, propondo que eles escrevam de forma coletiva, a gente dá a possibilidade de eles articularem melhor a ideia do pensar junto, como eles vão organizar a escrita. [...] Em todas as atividades que a gente faz, aposta-se muito no trabalho em grupo. Por exemplo, as salas são, nas séries iniciais, organizadas em grupos. Então, a todo momento, o aluno está construindo seu conhecimento a partir da interação que ele constrói com o outro e com o meio no qual ele está.

Mesmo entendendo que muitas das falas de estudantes, em suas declaraçôes ao jornal, podem idealizar tanto o processo quanto o próprio livro, o sentido positivo dado ao processo de produção dos textos não pode ser desprezado.

Minha mãe criou uma brincadeira para sempre que eu for ler alguma coisa. Ela me disse para ficar com dicionário do lado, para descobrir o que quer dizer uma palavra desconhecida. Sei que aprendo mais com o livro do que com o vídeo-game ou o computador e, para mim, ler é uma diversão. (Daniel, 7 anos)

Ainda podemos vicejar outras contribuiçôes significativas do trabalho desenvolvido ao longo dos anos desse projeto. Uma delas diz respeito à preocupação com a influência do texto sobre a vida de outros sujeitos, dos prós e dos contras que essa exposição poderia causar, demonstrando o lado socializante para o qual se destina a produção literária, sem perder de vista o componente de valorização pessoal que também carrega. 
Fiquei envergonhada quando a professora pediu que a gente cantasse a música (Hip Hop) também nas outras turmas, mas todo mundo gostou muito. Me senti importante mostrando o que a gente fez. Imagina se nosso texto vai para um livro? Acho que dou uma festa para comemorar. (Joana, 10 anos)

Há quatro anos escrevo um romance, mas não sei se vou conseguir publicá-lo. [...] Acho que tudo o que a gente escreve pode influenciar a vida de alguém e quando a gente é valorizada por compartilhar as nossas ideias, é muito gratificante. (Natália, 15 anos)

O próprio livro produzido nessa concepção passa a ser um objeto de uso vivo, cotidiano e passível de articulação com as temáticas desenvolvidas, inclusive, em anos posteriores. Ou seja, transformamos com material literário e didático de referência contextualizada.

A leitura e a escrita são trabalhadas de forma intensa aqui na escola. E um dos livros que utilizamos em sala é, justamente, a coletânea de redaçôes [...]. Isto vai ter como consequência um estímulo ainda maior para que eles leiam e escrevam mais. (Cristiane Oliveira)

Acrescentamos que os livros produzidos pelos estudantes do CAp-UERJ, fruto desse projeto de extensão, também possui impacto e reconhecimento institucional ao ser referenciado pelos conselhos e demais órgãos que compóem a Universidade na qual a escola se insere. Também o Conselho da instituição - composto por estudantes do grêmio escolar, professores e servidores técnico-administrativos -, participou, debatendo as temáticas dos diferentes anos e deliberando sobre elas. Nesse caso, em diversos momentos a presença de representantes institucionais importantes foi fundamental para reforçar na comunidade escolar o valor dos sujeitos envolvidos na ação, fossem eles os trabalhadores, os estudantes ou os pais.

A escolha do tema foi deliberada em conselho departamental da unidade. Ele foi escolhido em função da necessidade dos professores terem percebido a necessidade de resgatar, discutir e representar valores como ética, moral, cidadania. O que tentamos fazer no CA é incentivar os alunos a dividirem responsabilidades e somarem ações. (Lincoln Silva)

O professor evidencia ainda a possibilidade de o livro ser um instrumento para contar e recontar a história do Instituto, mantendo a instituição 
viva. Tal fato pode ser evidenciado na escolha institucional realizada no livro que marcou os 50 anos do CAp em 2007:

Desde 2004 nós trabalhamos temas variados e agora chegou a oportunidade de falarmos de nós mesmos, de falarmos sobre nossa própria instituição, aproveitando os 50 anos. Isso mantém a instituição viva, ela consegue trabalhar a diversidade, seja a diversidade de temas, de propostas, de olhares. [...] Daqui a um tempo, eles serão ex-alunos e vão se encontrar também nesses registros que estão deixando. (Jacqueline Morais)

Essas açóes se congregam a outras já desenvolvidas em espaços-tempo institucionais, privilegiando a leitura e a escrita como elementos fundamentais para o desenvolvimento do currículo escolar. Para tanto, em diferentes anos de escolaridade, nos diferentes segmentos do Ensino Fundamental e mesmo do Ensino Médio, há áreas do conhecimento que participam ativamente das açóes do projeto e que de alguma forma são influenciadas pela dinâmica impressa a partir de sua efetiva realização. Deste modo, as disciplinas Clube de Leitura e Redação adquirem focos de produção diferenciados e oportunizam aos estudantes espaços de escolha e de liberdade de expressão, que mais tarde são materializados nos textos publicados.

$\mathrm{Na}$ verdade, este espaço deveria se chamar Clube de leituras, porque o trabalho feito aqui é de educação do olhar: olhar para o livro, ou, por exemplo, para as marcas do tempo presentes nos equipamentos urbanos. Ou seja, a questão aqui é tratar a leitura do mundo. (Leila Medeiros)

Embora o envolvimento dos docentes e das disciplinas seja diferenciado, fios interdisciplinares acabam sendo expressos nos textos, o que permite mobilizar os saberes, tanto pelos professores quanto pelos alunos. Também ultrapassam os muros da escola, ao mobilizarem as famílias que têm acesso diretamente aos conhecimentos tecidos no cotidiano escolar, contextualizados e materializados na produção discente. Podemos registrar a fala de reconhecimento de alguns pais sobre o trabalho da escola na formação com qualidade de seus filhos. Tal perspectiva não atribui ao projeto uma característica de panaceia que absorve o cotidiano escolar ou transforma a realidade social resolvendo todos os problemas, mas aponta, com certeza, que a abordagem crítica e coletiva das questóes de nossa realidade pode ser feita com leveza, multiplicidade e exatidão, conforme já nos dissera o escritor Ítalo Calvino (1990). 
A proposta era escrever uma carta para uma empresa pedindo patrocínio para o CAp e eu escrevi o que o CAp está precisando e os meios para conseguir. (Carolina, 15 anos)

Quando apostamos em algo, tem que ser para a vida inteira. Meu filho sempre foi aluno desta escola e hoje me sinto feliz por ter confiado que uma escola pública pode e tem condiçóes de oferecer um ensino de qualidade. (Raquel, mãe de um estudante do CAp)

Mais do que prêmios, medalhas ou placas, o projeto tem recebido o reconhecimento da comunidade escolar. Autores, que talvez ainda não tenham a dimensão da importância de suas histórias, deixam um legado para aqueles que vêm e nos desafiam a continuar o projeto. Pensar e apontar as perspectivas do projeto "O livro e a formação do leitor-escritor" representa, portanto, pensar e apontar caminhos para sua continuidade.

Desta forma, nosso maior desejo é que esse projeto continue a estimular nossos estudantes e professores a refletir sobre a realidade, relendo-a, dando-lhe novos sentidos, a fim de construírem novos horizontes de possibilidades.

\section{Nota}

1. Optamos, neste artigo, por manter os nomes reais dos professores, já que eles autorizaram. Quanto aos alunos, utilizamos nomes fictícios.

\section{Referências}

BAKHTIN, M. Marxismo e filosofia da linguagem: problemas fundamentais do método sociológico na ciência da linguagem. São Paulo: Hucitec, 1981.

CALVINO, I. Seis propostas para o próximo milênio. São Paulo: Companhia das Letras, 1990.

GARCIA, R. L. (Org.). A formaçâo da professora alfabetizadora: reflexóes sobre a prática. 2. ed. Sáo Paulo: Cortez, 1998.

GERALDI, J. W. Linguagem e ensino: exercícios de militância e divulgação. Campinas, SP: Mercado de Letras-ALB, 1996. 
GRAMSCI, A. Os intelectuais e a organizaçâo da cultura. 7 ed. Rio de Janeiro: Civilização Brasileira, 1989.

QUINTANA, M. Do Caderno H. Porto Alegre: Editora Globo, Coleção Sagitário, 1973.

SANTOS, B. de S. A gramática do tempo. São Paulo: Cortez, 2006.

SPOSITO, M. P. A ilusão fecunda: a luta por educação nos movimentos populares. Sáo Paulo: Hucitec, 1993.

Recebido em: 20 dez. 2010

Aceito em: 26 ago. 2011 